\title{
PENELUSURAN ARSITEKTUR INDIS PADA STASIUN KERETA API BINJAI
}

\author{
Ludy Hartono ${ }^{1}$, Imam Faisal Pane ${ }^{2}$ \\ Program Studi Magister Teknik Arsitektur Fakultas Teknik Universitas Sumatera Utara \\ Jl. Perpustakaan St. J07 Building, Medan, 20155, Indonesia \\ *Email: ${ }^{1}$ lyho.lu@gmail.com, ${ }^{2}$ raihanpane@yahoo.com
}

\begin{abstract}
The colonial's architecture was spread in cities in Indonesia. It was influenced by the modern architecture that was emerging in Europe. For the time being, acculturation happened between the Dutch and the heterogeneous Indonesian. Its design adapted with the local condition and climate. Mostly, it is called by Indis Architecture. It was the result of the culture and lifestyle which was begun since the Dutch colony. As for example, Binjai Railway Station, which was established in 1887. This adapted two different culture, the Dutch and the Malays. This research describes Indis architecture in Binjai Railway Station by qualitative methods and descriptive approach. Data will be taken by observing form and architectural element of the building. As of it, Binjai Railway Staion adapted two different cultures which resulted in a new culture, Indis architecture.
\end{abstract}

Keywords: Colonial's Architecture, Indis Architecture, Dutch, Malays.

\section{PENDAHULUAN}

Peninggalan arsitektur kolonial cukup banyak tersebar di seluruh kota-kota di Indonesia. Dalam sejarah tercatat Indonesia dijajah oleh Belanda dan Jepang. Masa kolonialisme Belanda yang relatif lama (tiga setengah abad) dibanding dengan Jepang (tiga setengah tahun) lebih banyak meninggalkan fisik berupa tata kota dan bangunan-bangunan yang dikenal dengan arsitektur kolonial. Menurut Rachmawati, arsitektur kolonial adalah arsitektur yang dibangun selama masa kolonial, ketika Indonesia menjadi negara jajahan Belanda pada tahun 1600-1942, yaitu 350 tahun penjajahan Belanda di Indonesia (Gartiwa, 2011:98).

Menurut Sumalyo (1993:9), pembentukan arsitektur kolonial di Indonesia awalnya merupakan penerapan arsitektur yang mendapat pengaruh Eropa dan perkembangan arsitektur modern yang berkembang di sana. Seiring berjalannya waktu, terjadi pencampuran budaya antara Belanda yang telah lama menetap dengan budaya Indonesia yang beraneka ragam. Desain arsitektur Belanda yang memiliki kekhasan beradaptasi dengan kondisi lokal dan iklim setempat. Hal inilah yang membuat arsitektur kolonial di Indonesia menjadi fenomena budaya yang unik.

Arsitektur kolonial mempunyai gaya yang berbeda satu dengan lainnya sesuai dengan zaman didirikannya bangunan tersebut. Handinoto (1996) mengutip Helen Jessup yang membagi atas 4 periode perkembangan arsitektur kolonial Belanda di Indonesia, antara lain: (1) Abad 16 sampai tahun 1800-an, Indonesia masih disebut sebagai Netherland Indische (Hindia Belanda), saat itu arsitektur tidak mempunyai suatu orientasi bentuk yang jelas dan tidak beradaptasi dengan iklim dan lingkungan setempat; (2) Tahun 1800-an (awal abad ke-19) sampai tahun 1902, gaya Neoklasik yang melanda Eropa diadopsi ke Hindia Belanda dengan nama Indische Architectuur; (3) Tahun 1902 sampai tahun 1920-an, muncul standar arsitektur modern yang berorientasi ke Belanda; dan (4) Tahun 1920-an sampai tahun 1940-an, pendekatan rancangan arsitektur Hindia Belanda memegang unsur-unsur arsitektur tropis, arsitektur tradisional Indonesia sehingga menjadi konsep yang eklektis.

Sebutan arsitektur Indis merupakan wujud dari bangunan kolonial yang memiliki kekhasan beradaptasi dengan kondisi lokal dan iklim setempat. Menurut Soekiman (2000), arsitektur Indis awalnya merupakan pencampuran antara 
budaya Belanda (Eropa) dengan budaya Jawa (lokal) yang terjadi akibat proses akulturasi yang panjang. Seiring berjalannya waktu, arsitektur Indis menjadi cerminan gaya hidup yang dianut oleh sebagian kecil penghuni Nusantara pada masa kolonial. Arsitektur Indis bagi orang-orang Belanda merupakan sebuah jawaban terhadap tantangan alam tropis Nusantara. Sidharta (1997), memperjelas bahwa arsitektur Indis sebenarnya berarti arsitektur yang dibangun selama waktu pemerintahan kolonial Belanda di Indonesia antara abad 17 sampai tahun 1942 yang dipengaruhi oleh arsitektur Belanda (Sukawi, 2009:44).

Stasiun Kereta Api Binjai yang telah berdiri sejak tahun 1887 merupakan salah satu peninggalan arsitektur kolonial Belanda. Rentang waktu berdirinya Stasiun Kereta Api Binjai pada masa pemerintahan Hindia Belanda dapat digolongkan sebagai arsitektur Indis. Arsitektur Indis pada bangunan ini dapat dideskripsikan dari adaptasi dua kebudayaan berbeda, yaitu kebudayaan kolonial Belanda dan kebudayaan lokal Melayu.

Penelitian ini membahas penelusuran arsitektur Indis pada Stasiun Kereta Api Binjai yang masih melekat hingga saat ini. Tujuan dari penelitian ini adalah menemukan aplikasi konsep dan elemen arsitektur kolonial Belanda, serta menemukan adanya penerapan arsitektur lokal Melayu pada Stasiun Kereta Api Binjai.

\section{METODOLOGI PENELITIAN}

Penelitian terhadap penelusuran arsitektur Indis pada Stasiun Kereta Api Binjai menggunakan metode penelitian kualitatif dan pendekatan secara deskriptif. Pengumpulan data dilakukan melalui penggambaran ulang sesuai dengan kondisi saat ini (as built draw), pendokumentasian dengan menggunakan kamera, serta observasi langsung dengan melakukan pengamatan bentuk bangunan dan elemen arsitektural pada Stasiun Kereta Api Binjai.

Adapun metode penentuan variabel ditentukan dengan terlebih dahulu menetapkan teori yang menjadi basis dalam menemukan indikator. Indikator yang dijadikan sebagai variabel oleh peneliti tentunya mengacu kepada penelusuran arsitektur Indis pada Stasiun Kereta Api Binjai agar dapat menjawab permasalahan penelitian sesuai yang telah dideskripsikan (Tabel 1).

Tabel 1. Cara Menentukan Variabel

\begin{tabular}{|c|c|c|c|}
\hline Teori & Variabel & Data yang diperlukan & $\begin{array}{c}\text { Metode Pengumpulan } \\
\text { Data }\end{array}$ \\
\hline $\begin{array}{l}\text { Konsep arsitektur kolonial di } \\
\text { Hindia Belanda terlihat pada } \\
\text { denah, tampak, pemakaian } \\
\text { bahan bangunan, serta sistem } \\
\text { konstruksi yang dipakai } \\
\text { (Hartono \& Handinoto, } \\
\text { 2006:91). }\end{array}$ & $\begin{array}{l}\text { 1. Denah } \\
\text { 2. Tampak } \\
\text { 3. Pemakaian bahan } \\
\text { bangunan } \\
\text { 4. Sistem konstruksi } \\
\text { yang dipakai }\end{array}$ & $\begin{array}{l}\text { 1. Gambar denah } \\
\text { 2. Gambar tampak } \\
\text { 3. Material yang } \\
\text { dipakai } \\
\text { 4. Konstruk-si yang } \\
\text { dipakai }\end{array}$ & $\begin{array}{l}\text { 1. As built draw Stasiun } \\
\text { Kereta Api Binjai } \\
\text { 2. Pengama-tan lang- } \\
\text { sung pada Stasiun } \\
\text { Kereta Api Binjai } \\
\text { 3. Pendoku-mentasian } \\
\text { dengan kamera }\end{array}$ \\
\hline $\begin{array}{l}\text { Elemen arsitektur kolonial di } \\
\text { Hindia Belanda terlihat pada } \\
\text { gable, tower, dormer, } \\
\text { windwijzer, nok acroterie, } \\
\text { balustrade, dan ragam hias } \\
\text { pada tubuh bangunan } \\
\text { (Gartiwa, 2011:100-101). }\end{array}$ & $\begin{array}{l}\text { 1. Gable } \\
\text { 2. Tower } \\
\text { 3. Dormer } \\
\text { 4. Windwij-zer } \\
\text { 5. Nok acroterie } \\
\text { 6. Balus-trade } \\
\text { 7. Ragam hias pada } \\
\text { tubuh bangunan }\end{array}$ & $\begin{array}{l}\text { 1. Unsur gable } \\
\text { 2. Unsur tower } \\
\text { 3. Unsur dormer } \\
\text { 4. Unsur windwij-zer } \\
\text { 5. Unsur nok acroterie } \\
\text { 6. Unsur balus-trade } \\
\text { 7. Unsur ragam hias } \\
\text { pada Stasiun Kereta } \\
\text { Api Binjai }\end{array}$ & $\begin{array}{l}\text { 1. Pengama-tan lang- } \\
\text { sung penggu-naan } \\
\text { elemen arsitektur } \\
\text { kolonial pada Stasiun } \\
\text { Kereta Api Binjai } \\
\text { 2. Pendoku-mentasian } \\
\text { dengan kamera }\end{array}$ \\
\hline $\begin{array}{l}\text { List-plank, pintu, jendela, } \\
\text { tiang, dan ornamen } \\
\text { merupakan bagian penting } \\
\text { yang menyandang identitas } \\
\text { bangunan Melayu (Wahid \& } \\
\text { Alamsyah, 2013:22). }\end{array}$ & $\begin{array}{l}\text { 1. List-plank } \\
\text { 2. Pintu } \\
\text { 3. Jendela } \\
\text { 4. Tiang } \\
\text { 5. Onamen }\end{array}$ & $\begin{array}{l}\text { 1. Penggu-naan list- } \\
\text { plank pada atap } \\
\text { 2. Bentuk Pintu } \\
\text { 3. Bentuk Jendela } \\
\text { 4. Unsur Tiang } \\
\text { 5. Ornamen yang } \\
\text { dipakai }\end{array}$ & $\begin{array}{l}\text { 1. Pengama-tan lang- } \\
\text { sung pada Stasiun } \\
\text { Kereta Api Binjai } \\
\text { 2. Pendoku-mentasian } \\
\text { dengan kamera }\end{array}$ \\
\hline
\end{tabular}




\section{HASIL DAN PEMBAHASAN}

\section{Tanggap Terhadap Iklim Tropis}

Stasiun Kereta Api Binjai dibangun dengan beberapa penyesuaian dalam menanggapi iklim tropis Indonesia. Iklim di Indonesia berubah sepanjang tahun ditandai dengan pergantian musim kemarau dan penghujan. Kondisi ini memungkinkan terjadinya kontak alam dengan fisik Stasiun Kereta Api Binjai. Hasil perancangan Stasiun Kereta Api Binjai kelihatannya telah menunjukkan bukti bahwa bangunan ini telah direncanakan dengan menanggapi iklim tropis sejak awal hingga saat ini.

Denah pada Stasiun Kereta Api Binjai memvisualisasikan bentuk bangunan yang ramping. Hal ini memungkinkan penggunaan bukaan yang banyak pada sekeliling bangunan, sehingga memudahkan pergantian udara (cross ventilation) yang sangat diperlukan iklim tropis basah (Gambar 1).

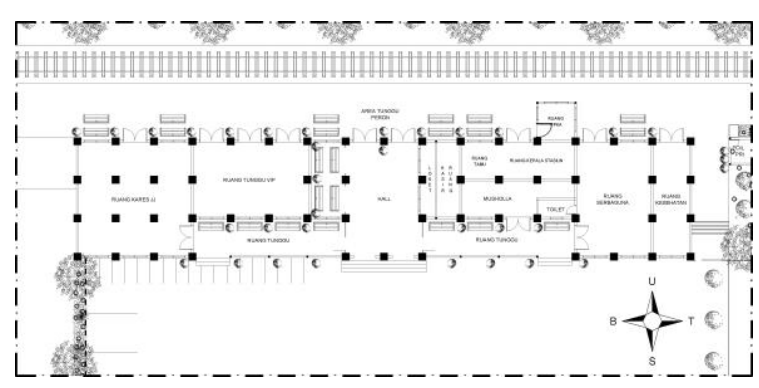

Gambar 1. Orientasi Bangunan Stasiun Kereta Api Binjai

Selasar pada Stasiun Kereta Api Binjai dapat berfungsi untuk menghindari tampias air hujan dan sinar matahari langsung (Gambar 2). Hal ini juga didukung dengan denah yang menghadap utara-selatan dengan orientasi tepat terhadap sinar matahari tropis timur-barat.

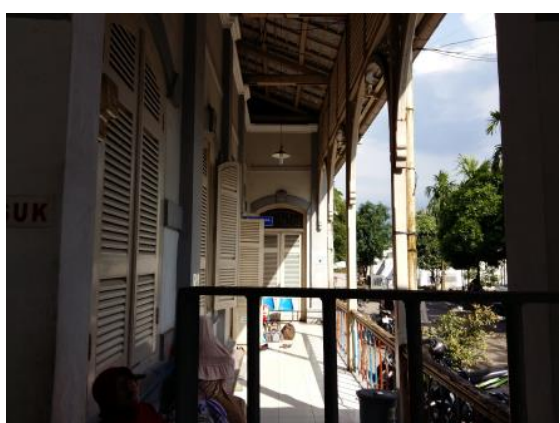

Gambar 2. Selasar pada Stasiun Kereta Api Binjai

\section{Denah dan Tampak}

Sumbu simetri jelas terlihat pada denah Stasiun Kereta Api Binjai. Simetri merupakan salah satu konsep arsitektur kolonial yang cukup banyak diterapkan pada Indische Empire (Abad 18-19) dan arsitektur transisi (1890-1915) (Hartono \& Handinoto, 2006:91). Stasiun Kereta Api Binjai yang dibangun pada rentang waktu itu (1887) terlihat mengikuti konsep simetri tersebut (Gambar 3). Jika ditarik garis lurus pada bagian pintu masuk (tengah) bangunan, akan terlihat sumbu yang menunjukkan penerapan simetri pada Stasiun Kereta Api Binjai.

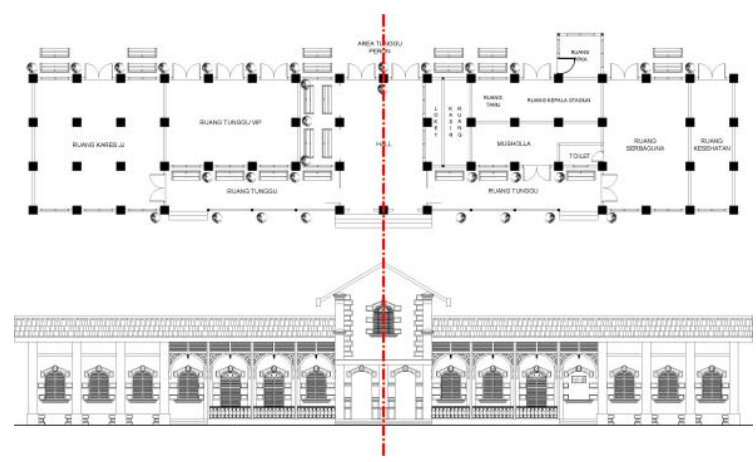

Gambar 3. Sumbu Simetri pada Denah dan Tampak Stasiun Kereta Api Binjai

\section{Bahan Bangunan dan Sistem Konstruksi}

Penggunaan bahan bangunan utama pada Stasiun Kereta Api Binjai berupa batu bata yang digunakan pada dinding, serta kayu yang digunakan pada tiang, pintu, jendela, dan atap. Material batu bata ini sebagian besar masih dapat terlihat pada bagian atas ornamen yang melintang disepanjang peron (Gambar 4). Sistem konstruksi berupa dinding pemikul yang menggunakan dinding sebagai penopang struktur utama selain sebagai pembatas ruang. Selain itu penggunaan konstruksi gable juga terlihat pada bagian pintu masuk Stasiun Kereta Api Binjai.

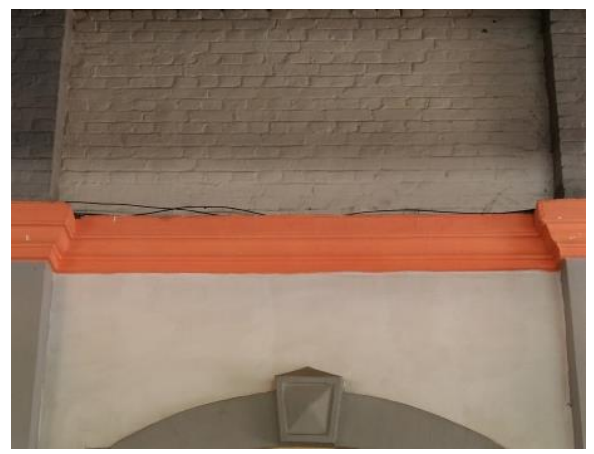


Gambar 4. Material Batu Bata yang Digunakan Gable dan Tower

Pada bagian pintu masuk terdapat gable yang menjadi ciri dari Stasiun Kereta Api Binjai (Gambar 5, dan 6). Gable pada bangunan ini terlihat menyatu dengan tower yang menghadap sisi utara dan selatan. Pada bagian tower terdapat jendela yang berfungsi untuk memasukkan cahaya ke dalam ruang lobby yang ada di bawahnya. Gable juga terlihat digunakan pada bagian samping bangunan (sisi timur dan barat). Penggunaan gable terlihat digunakan pada arsitektur transisi (Hartono \& Handinoto, 2006:91).

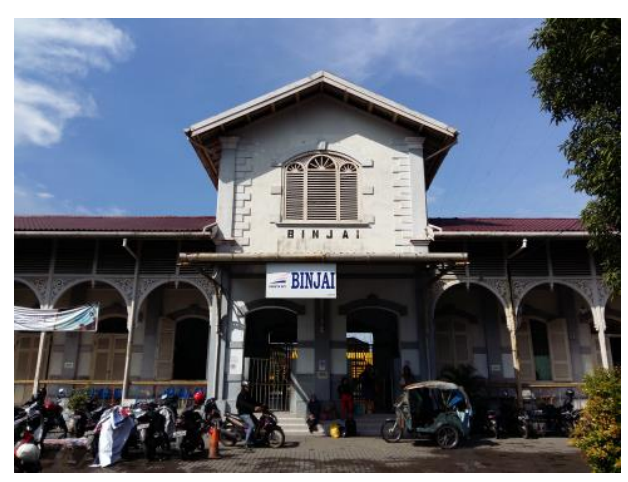

Gambar 5. Gable dan Tower pada Bagian Pintu Masuk Stasiun Kereta Api Binjai

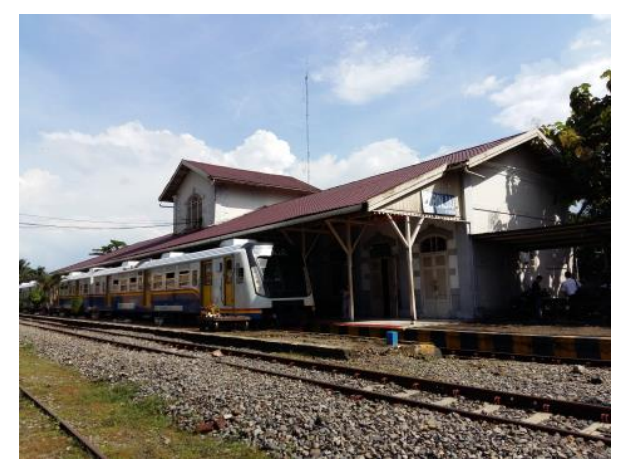

Gambar 6. Gable pada Bagian Barat Stasiun Kereta Api Binjai

\section{Balustrade}

Elemen arsitektur lainnya berupa penggunaan balustrade yang hanya terlihat pada selasar depan Stasiun Kereta Api Binjai. Balustrade ini berfungsi sebagai pembatas agar tidak terjatuh ke bawah. Balustrade ini ditopang oleh besi-besi lurus yang ditancapkan pada lantai dengan motif setengah lingkaran maupun lingkaran penuh. Bagian pegangan balustrade terbuat dari bahan kayu yang telah diukir (Gambar 7).

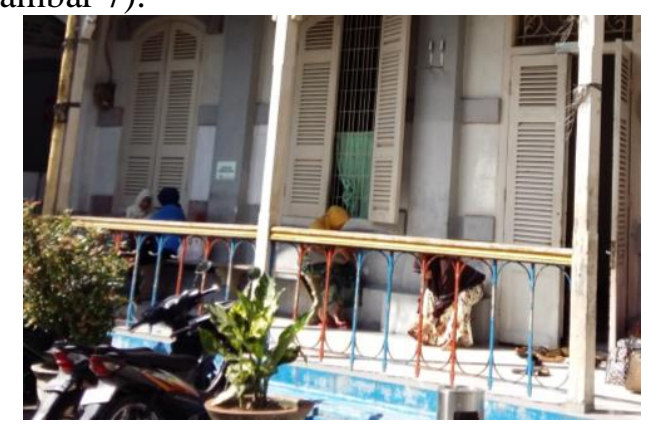

Gambar 7. Balustrade di Selasar Depan Stasiun Kereta Api Binjai

\section{Pintu dan Jendela Double Swing}

Keseluruhan pintu (Gambar 8) dan jendela (Gambar 9) pada Stasiun Kereta Api Binjai menggunakan double swing.

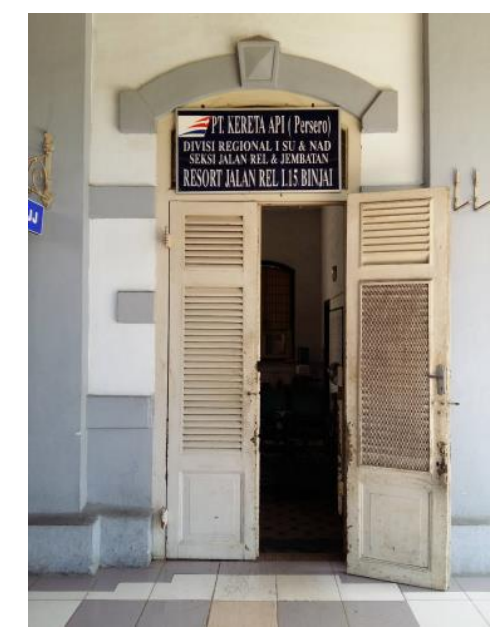

Gambar 8. Pintu Double Swing pada Stasiun Kereta Api Binjai

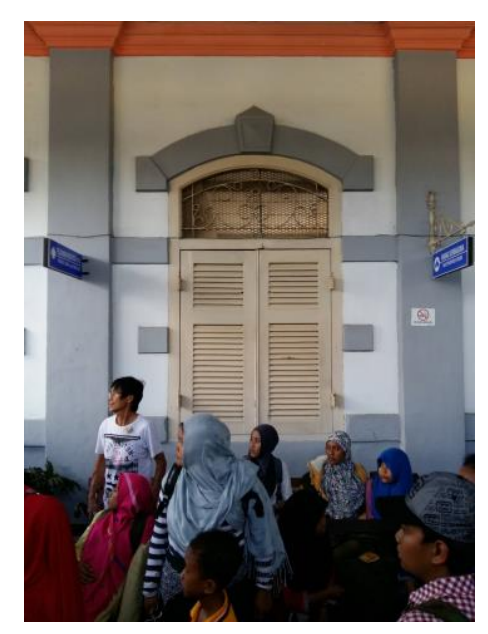

Gambar 9. Jendela Double Swing pada Stasiun Kereta Api Binjai 


\section{Bovenlicht}

Pada bagian atas pintu dan jendela terdapat bovenlicht yang juga menambah ragam hias pada Stasiun Kereta Api Binjai. Hampir keseluruhan bukaan menggunakan bovenlicht yang berguna mengalirkan udara dan memasukkan cahaya ke dalam ruangan (Gambar $10)$.

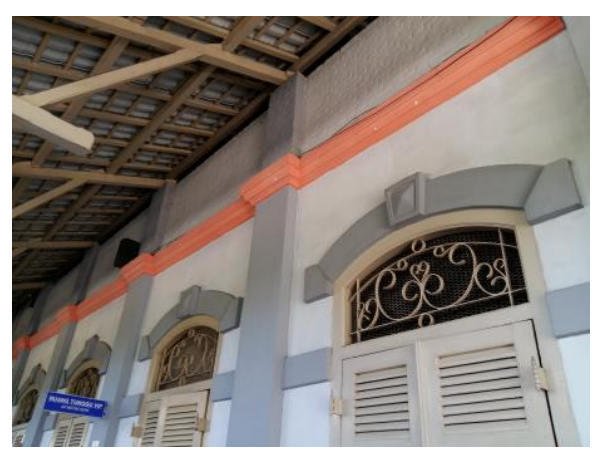

Gambar 10. Bovenlicht pada Pintu dan Jendela Stasiun Kereta Api Binjai

\section{Molding, Hood Molding, Dado, dan Plinth}

Pada Gambar 11, 12, 13, dan 14 menjelaskan ornamen pada Stasiun Kereta Api Binjai banyak menggunakan ornamen arsitektur kolonial Belanda yang diadopsi dari perkembangan arsitektur di Eropa. Penggunaan ornamen banyak terlihat digunakan pada dinding. Hood molding terlihat menonjol di atas pintu dan jendela pada Stasiun Kereta Api Binjai. Ornamen ini mudah dijumpai pada bagian atas keseluruhan pintu dan jendela Stasiun Kereta Api Binjai. Pada bagian lobby stasiun ini terdapat dado yang ditunjukkan pada bagian bawah dinding (warna abu) yang diperlakukan berbeda dari bagian atasnya. Selain itu terdapat plinth di sepanjang dinding peron Stasiun Kereta Api Binjai.

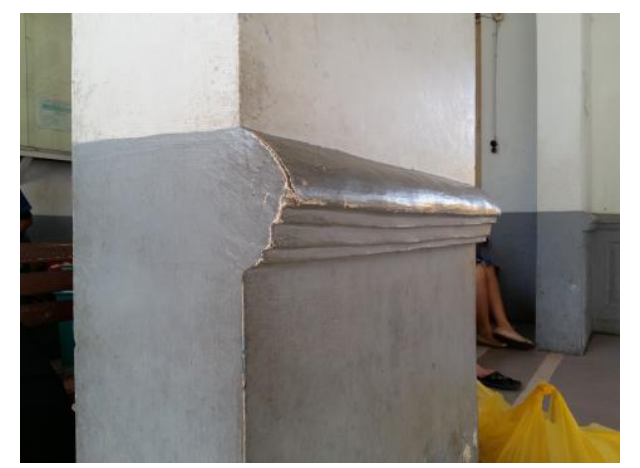

Gambar 11. Molding pada Dinding Stasiun Kereta

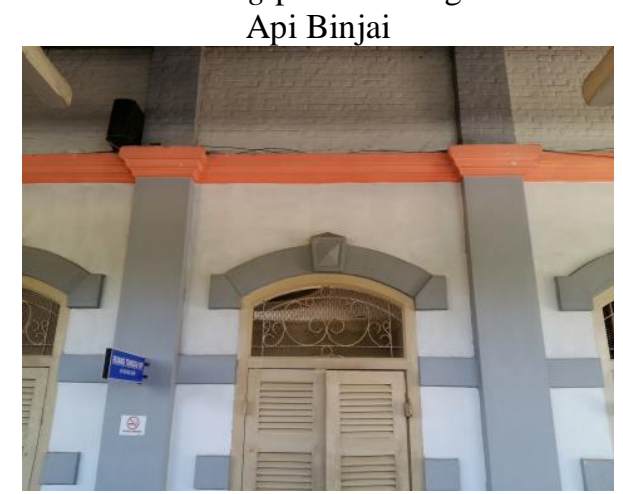

Gambar 12. Hood Molding pada Pintu dan Jendela Stasiun Kereta Api Binjai

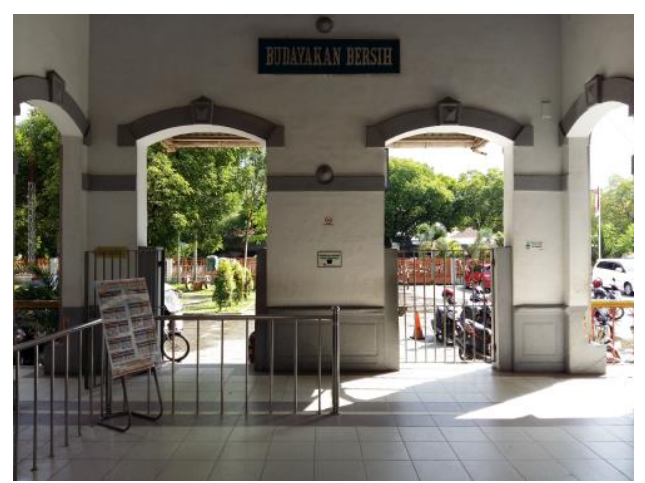

Gambar 13. Dado pada Dinding Stasiun Kereta Api Binjai

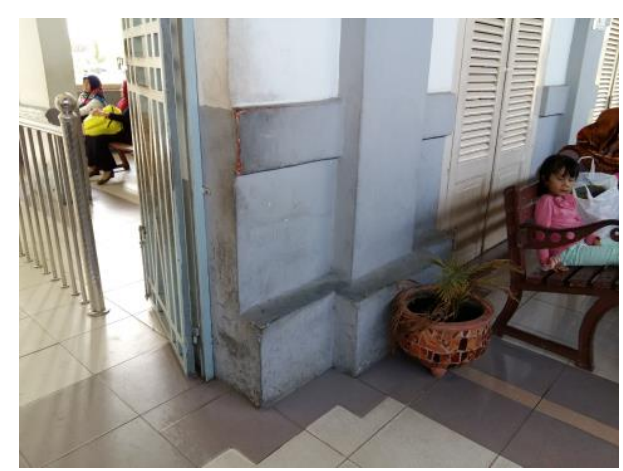

Gambar 14. Plinth pada Dinding Peron Stasiun Kereta Api Binjai

\section{List-plank}

List-plank merupakan bagian penting yang menyandang identitas bangunan Melayu (Wahid \& Alamsyah, 2013:22). Fungsi dari listplank ini sebagai penutup atap di bagian ujung, pengarah angin, dan juga bagian penyangga atap. Penggunaan list-plank dengan ornamen lebah gantung pada Stasiun Kereta Api Binjai hanya terlihat pada atap peron (Gambar 15). 


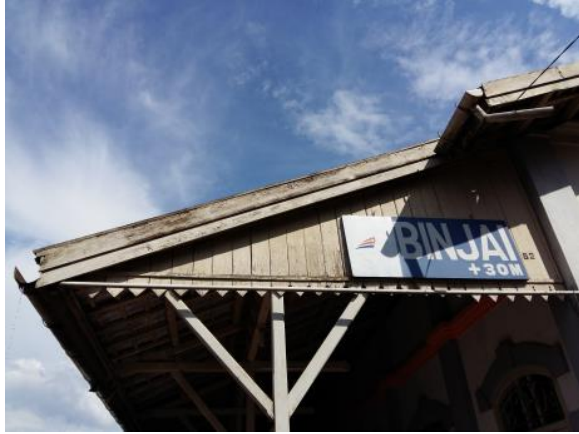

Gambar 15. List-plank pada Atap Peron Stasiun Kereta Api Binjai

\section{Lubang Angin}

Penggunaan lubang angin sesuai dengan arsitektur Melayu yang tanggap terhadap iklim tropis Indonesia untuk mengalirkan udara dan memasukkan cahaya ke dalam ruangan. Pada arsitektur kolonial lubang angin lebih dikenal dengan bovenlicht. Pada bagian lubang angin dibuat motif berupa sulur-sulur tanaman yang juga merupakan ciri dari arsitektur Melayu (Gambar 16).

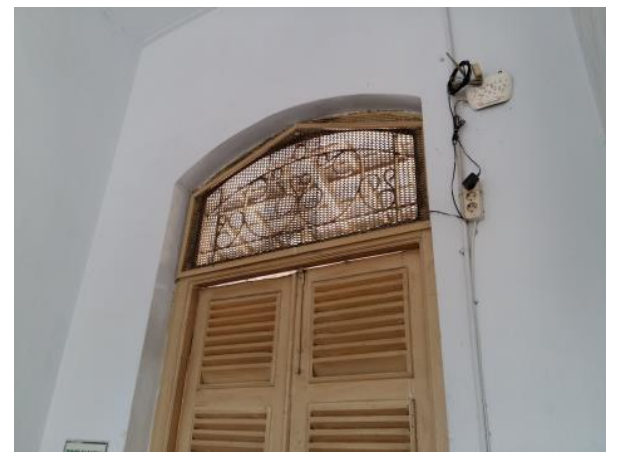

Gambar 16. Lubang Angin di Atas Pintu Stasiun Kereta Api Binjai

\section{Pintu dan Jendela Jalusi}

Jendela dalam kata asli Melayu disebut sebagai tingkap atau kauri. Pintu dan jendela yang digunakan terbuat dari kayu yang membentuk jalusi berupa sirip miring untuk mengalirkan udara ke dalam ruangan dan memberikan privasi. Pintu dan jendela pada Stasiun Kereta Api Binjai keseluruhan dibuka mengarah ke sisi luar bangunan. Pada umumnya bukaan yang dipasang pada bangunan Melayu memang terbuka ke arah luar. Bentuk jendela memanjang ke atas dengan tinggi mencapai 6 kaki dan lebar 1,5 kaki (Wahid \& Alamsyah, 2013:23) (Gambar 17).

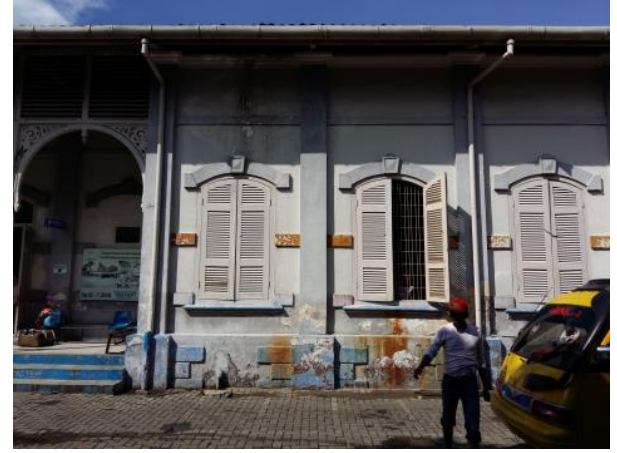

Gambar 17. Jendela/Tingkap pada Stasiun Kereta Api Binjai

\section{Tiang}

Tiang merupakan elemen lainnya yang dapat dikenali dari arsitektur Melayu. Tiang dominan dijumpai pada peron Stasiun Kereta Api Binjai. Tiang ini berfungsi untuk menopang atap di atasnya. Tiang sebagai bagian yang terpenting dalam konstruksi terbuat dari kayu dengan kualitas yang baik. Bagian atas tiang terlihat menggunakan sistem gapit (Gambar 18, 19).

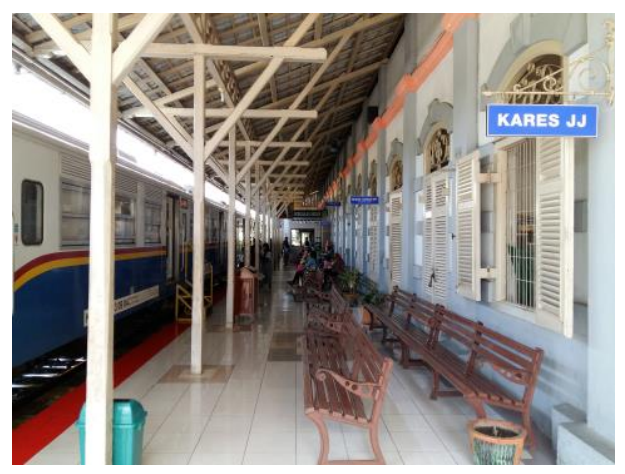

Gambar 18. Deretan Tiang pada Peron Stasiun Kereta Api Binjai

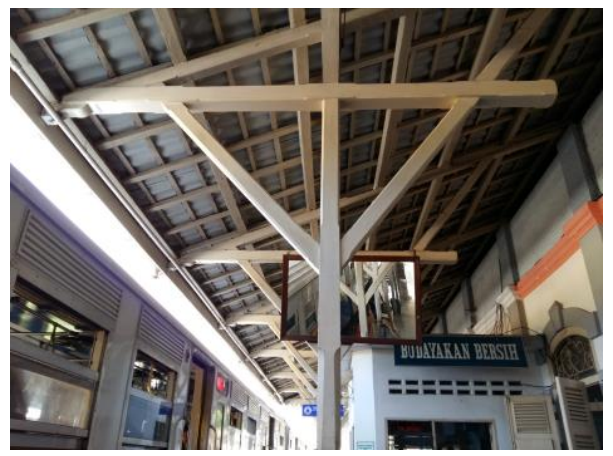

Gambar 19. Sambungan Kayu pada Tiang Peron Stasiun Kereta Api Binjai 


\section{Ornamen}

Gambar 20-22 adalah ragam ornamen yang sering digunakan pada arsitektur Melayu adalah motif tumbuhan berupa bentuk sulur, bentuk daun, bunga, dan grafis geometris (Wahid \& Alamsyah, 2013:23). Salah satu ornamen yang dapat dijumpai pada Stasiun Kereta Api Binjai adalah ornamen silang yang terbentuk dari bentuk grafis geometris. Ornamen ini dapat terlihat pada bagian atas tiang sepanjang peron dan pada jendela tower Stasiun Kereta Api Binjai.

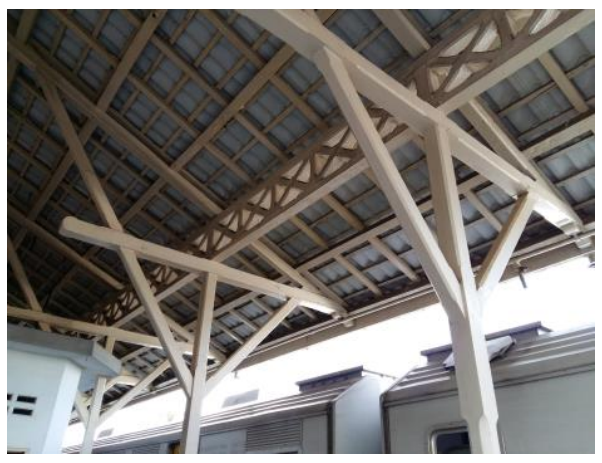

Gambar 20. Ornamen Silang di Atas Tiang Peron Stasiun Kereta Api Binjai

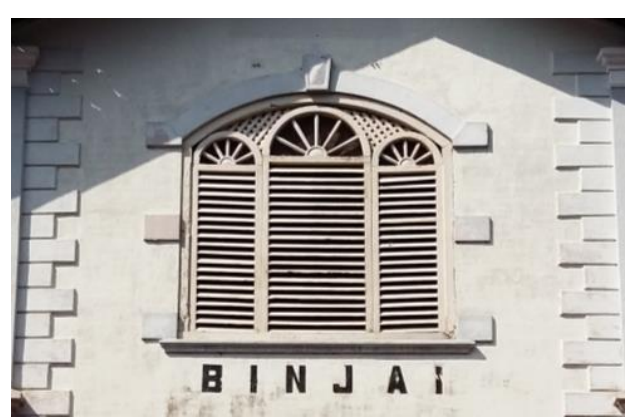

Gambar 21. Ornamen Silang pada Jendela Tower Stasiun Kereta Api Binjai

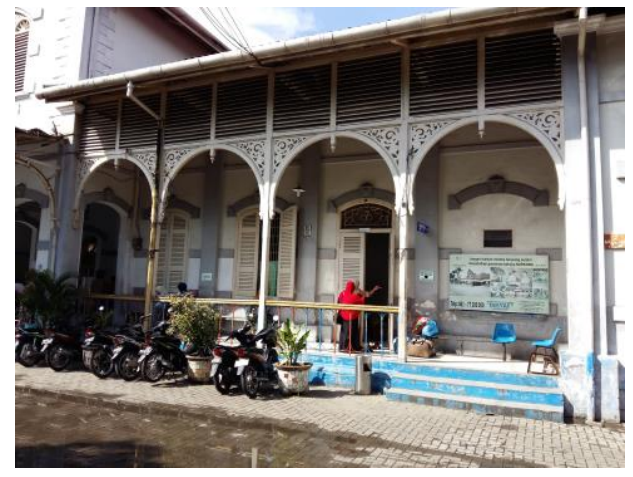

Gambar 22. Ornamen Melayu pada Bagian Selasar Depan Stasiun Kereta Api Binjai

Selain ornamen silang, terlihat pula ornamen berupa motif sulur tanaman. Ornamen ini diapit di antara tiang selasar depan Stasiun Kereta Api Binjai. Bingkai luar ornamen ini membentuk setengah lingkaran dengan hiasan ukiran pada bagian ujungnya (Gambar 23).

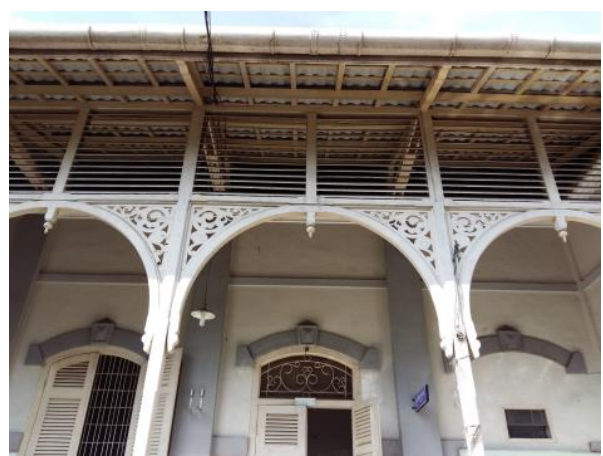

Gambar 23. Ornamen Melayu di Antara Tiang Selasar Depan Stasiun Kereta Api Binjai

Berdasarkan pengamatan yang telah dilakukan, penelusuan peneliti terhadap arsitektur Indis pada Stasiun Kereta Api Binjai dapat dijabarkan pada Tabel 2.

Tabel 2. Penelusuran Arsitektur Indis pada Stasiun Kereta Api Binjai

\begin{tabular}{ll}
\multicolumn{1}{c}{ Aspek } & \\
Arsitektur Indis & \multicolumn{1}{c}{ Penelusuran } \\
Denah & $\begin{array}{l}\text { Denah pada Stasiun Kereta Api Binjai menunjukkan konsep simetri ditandai dengan } \\
\text { sumbu pada ruang lobby. } \\
\text { Tampak depan Stasiun Kereta Api Binjai juga menunjukkan konsep simetri dengan } \\
\text { adanya tower pada bagian pintu masuk. }\end{array}$ \\
Material & $\begin{array}{l}\text { Material pada Stasiun Kereta Api Binjai didominasi dengan penggunaan batu bata } \\
\text { pada dinding dan penggunaan kayu pada pintu, jendela, serta ornamen. }\end{array}$ \\
Konstruksi & $\begin{array}{l}\text { Konstruksi pada Stasiun Kereta Api Binjai menggunakan konstruksi dinding pemikul. } \\
\text { Gable terlihat menyatu dengan tower pada bagian depan Stasiun Kereta Api Binjai, } \\
\text { selain itu juga terdapat di sisi samping bangunan. }\end{array}$ \\
\hline
\end{tabular}


Tabel 2. (Lanjutan)

\begin{tabular}{|c|c|}
\hline $\begin{array}{c}\text { Aspek } \\
\text { Arsitektur Indis }\end{array}$ & Penelusuran \\
\hline Tower & $\begin{array}{l}\text { Tower terdapat pada bagian tengah sebagai pintu masuk pada Stasiun Kereta Api } \\
\text { Binjai. }\end{array}$ \\
\hline Dormer & Tidak ditemukan \\
\hline Windwijzer & Tidak ditemukan \\
\hline Nok acroterie & Tidak ditemukan \\
\hline Balustrade & Balustrade hanya terdapat pada selasar depan Stasiun Kereta Api Binjai \\
\hline Ragam hias & Ragam hias pada tubuh bangunan Stasiun Kereta Api Binjai antara lain: \\
\hline pada tubuh bangunan & $\begin{array}{l}\text { 1. Pintu dan Jendela Double Swing yang digunakan pada sisi bangunan yang } \\
\text { menghadap utara-selatan. } \\
\text { 2. Bovenlicht di atas pintu dan jendela untuk mengalirkan udara. } \\
\text { 3. Penggunaan molding, hood molding, dado, dan plinth pada Stasiun Kereta Api } \\
\text { Binjai yang mendapat pengaruh dari perkembangan arsitektur di Eropa. }\end{array}$ \\
\hline List-plank & $\begin{array}{l}\text { List-plank dengan ornamen lebah gantung terdapat pada atap peron Stasiun Kereta } \\
\text { Api Binjai. }\end{array}$ \\
\hline Pintu & $\begin{array}{l}\text { Keseluruhan pintu pada Stasiun Kereta Api Binjai menggunakan jalusi untuk } \\
\text { mengalirkan udara ke dalam ruangan dan memberi privasi. }\end{array}$ \\
\hline Jendela & $\begin{array}{l}\text { Keseluruhan jendela / tingkap pada Stasiun Kereta Api Binjai menggunakan jalusi dan } \\
\text { dibuka mengarah ke sisi luar bangunan. }\end{array}$ \\
\hline Tiang & $\begin{array}{l}\text { Penggunaan tiang dari bahan kayu yang menjadi ciri arsitektur Melayu digunakan } \\
\text { pada peron Stasiun Kereta Api Binjai }\end{array}$ \\
\hline Ornamen & $\begin{array}{l}\text { Ornamen yang digunakan pada Stasiun Kereta Api Binjai antara lain: } \\
\text { 1. Ornamen lebah gantung dijumpai pada list-plank atap peron Stasiun Kereta Api } \\
\text { Binjai. } \\
\text { 2. Ornamen silang berupa grafis geometris yang djumpai pada jendela tower dan } \\
\text { pada bagian atas tiang sepanjang peron Stasiun Kereta Api Binjai. } \\
\text { 3. Ornamen sulur tanaman dijumpai pada bovenlicht dan di antara tiang selasar } \\
\text { depan Stasiun Kereta Api Binjai. }\end{array}$ \\
\hline
\end{tabular}

Penemuan adanya konsep dan elemen arsitektur kolonial Belanda maupun arsitektur lokal Melayu merupakan wujud dari arsitektur Indis pada Stasiun Kereta Api Binjai yang cukup mudah ditelusuri dan masih melekat pada fisik bangunannya hingga saat ini.

\section{PENUTUP}

Arsitektur Indis pada Stasiun Kereta Api Binjai ditandai dengan penggunaan konsep dan elemen arsitektur kolonial, serta elemen arsitektur lokal Melayu. Tanggapan terhadap iklim tropis pada bangunan ini merupakan suatu bentuk adaptasi dari budaya lokal Melayu. Terlihat pada tampilan bangunan menghadap utara-selatan dengan orientasi memanjang tepat mengikuti arah matahari tropis timur-barat. Tidak semua elemen arsitektur kolonial terdapat pada Stasiun Kereta Api Binjai, diantaranya tidak ditemukan adanya penggunaan dormer, windwijzer, maupun nok acroterie. Secara keseluruhan arsitektur Indis pada Stasiun Kereta Api Binjai merupakan perwujudan harmonis budaya baru dari pertukaran dua budaya yang berbeda berupa arsitektur kolonial Belanda, dan arsitektur lokal Melayu.

\section{UCAPAN TERIMA KASIH}

Dalam kesempatan ini peneliti mengucapkan terima kasih kepada Bapak Imam Faisal Pane, ST, MT, selaku pendamping dalam melakukan penelitian ini, juga saudari Vivianty, mahasiswi arsitektur ISTP angkatan 2011 yang membantu as built draw Stasiun Kereta Api Binjai.

\section{Daftar Pustaka}

Gartiwa, Marcus (2011) Morfologi Bangunan Dalam Konteks Kebudayaan. Bandung: Penerbit Muara Indah.

Handinoto (1996) Perkembangan Kota dan Arsitektur Kolonial Belanda di Surabaya (1870-1940). Yogyakarta: Penerbit Andi dan Universitas Kristen Petra Surabaya. 
Soekiman, Djoko (2000) Kebudayaan Indis dan Gaya Hidup Masyarakat Pendukungnya di Jawa (Abad XVIII-Medio Abad XX). Yogyakarta: Yayasan Benteng Budaya.

Sukawi (2009) Pengaruh Arsitektur Indis pada Rumah Kauman Semarang. Tesa Arsitektur, Vol. 7, No. 1 (Juni), hlm. 4150 .

Sumalyo, Yulianto (1993) Arsitektur Kolonial Belanda di Indonesia. Yogyakarta: Gadjah Mada University Press.

Wahid, Julaihi \& Alamsyah, Bhakti (2013) Arsitektur \& Sosial Budaya Sumatera Utara. Yogyakarta: Graha Ilmu. 